\title{
DEVELOPMENT OF ADHESION TEST FOR COATED MEDICAL DEVICE
}

Torda László Sélley ${ }^{1}$, Andrew Attila Terdik ${ }^{1}$, Eszter Bognár ${ }^{1,2}$

${ }^{1}$ Department of Materials Science and Engineering, Faculty of Mechanical Engineering, Budapest

University of Technology and Economics

${ }^{2}$ MTA-BME Research Group for Composite Science and Technology

torda90@gmail.com

\begin{abstract}
High biocompatibility is a basic requirement in medical technology. Polymer coatings can radically improve medical device biocompatibility, especially for surfaces like stainless steel. Adhesion is an important quality in a coating, and this was our rationale for developing a polymer adhesion testing protocol. We compared two biocompatible polymers, polyurethane (PUR) and poly-(DL-lactic-co-glycolic acid) (PDLG). Polymer layers were created on surface-treated stainless steel. The properties of different layers were compared. Adhesion of the coatings was characterised by concentration of coating solution, rate of the contacted surface and surface roughness of the carriers. PUR showed better adhesion under our test conditions.
\end{abstract}

Keywords: adhesion, biocompatible polymer, coating, PUR, PLGA

\section{Introduction}

Coatings are widely applied in the field of medical technology. Implants, surgical instruments and other medical devices can be provided with coatings. ${ }^{1}$ Coatings can improve some surface properties such as biocompatibility, and this is especially the case with polymer coatings. ${ }^{2}$ Polymer coatings generally make devices more bio - and haemocompatible, as well as more corrosion-resistant. Polymer coatings are also able to store and release active agents such as drugs. Another important property is adhesion to the carrier. Applied coatings are thin films with a micro-meter scale thickness. ${ }^{3}$ There is a wide variety of existing adhesion measurements, like bending, capitation, impact test, etc. ${ }^{4}$ Scratch tests and AFM for adhesion testing are used for measuring thin layer/carrier interaction like polymer coatings. ${ }^{5-7}$ Scratch tests are impractical and slow, especially if we want to examine layers we are developing ourselves. In this paper we test the adhesion of two kinds of polymers using a method we developed. ${ }^{8-9}$ We further developed the method considering the size of the contacting areas. For a carrier we chose stainless steel, a commonly used raw material in biomedical devices. Stainless steel 304 is used where high corrosion resistance, good formability, strength, manufacturing precision, reliability and hygiene are of particular importance. ${ }^{10}$

One polymer we tested as a coating was PUR. PUR is gathering pace as a coating in medical devices. Polyurethanes offer very high strength, high flexibility and proven impact resistance. ${ }^{11}$

The other polymer we tested was PDLG. It has been successful as a biodegradable polymer because it undergoes hydrolysis in the body to produce the original monomers, lactic acid and glycolic acid. These two monomers are easily broken down in the body without toxic effects, so this polymer is also biocompatible. ${ }^{12-13}$ 
Layers were made by dip-coating. This is the commonest and easiest technique for creating a continuous layer. ${ }^{14}$ We created a polymer layer on a surface-treated 304 type stainless steel carrier and compared the properties of different coatings. Adhesion of the coatings were characterised by concentration of coating solution, area of contact, and carrier surface roughness.

\section{Methods}

\subsection{Carrier sheets}

During our examinations we used two sorts of coating carriers, $0.3 \times 10 \times 50 \mathrm{~mm}$ (narrower) and $0.3 \times 20 \times 50 \mathrm{~mm}$ (broader) 304 type stainless steel sheets. Sheets were prepared by laser cutting. Sheets were surface-treated to improve their surface properties.

\subsection{Surface treatment}

First we removed the burr and surface damage from laser cutting. Hydrochloric acid (36 wt \%), nitric acid (65 wt \%) and water in a 3:1:9 mixture was used as an etching solution. Sheets were etched in the mixture for 60 minutes in an ultrasonic cleaning vat. Then sheets were electropolished in order to improve surface properties and to reduce roughness. Phosphoric acid (85 wt \%) sulphuric acid (98 wt \%) and water in a 3:6:1 mixture with 20g/L glycerol was used as the electrolyte. For electropolishing we applied $0.01 \mathrm{~A} / \mathrm{mm}^{2}$ current density at room temperature $\left(\sim 25^{\circ} \mathrm{C}\right)$ for 180,210 , and 240 seconds.

\subsection{Surface roughness}

We measured the surface roughness of the surface-treated stainless steel sheets. Based on preliminary tests we wanted to observe the connection of surface roughness to adhesion in both kinds of polymer. A Talysurf CLI 2000 scanning-topography measurement instrument was used to determine the surface-treated sheets' surface roughness. Needle speed was $50 \mu \mathrm{m} / \mathrm{second}$, geometry of the needle was $90^{\circ}$. A 4 to $4.75 \mathrm{~mm}$ area was examined on every 3-3 sample.

\subsection{Applied polymers}

During our experiments we used two types of biocompatible polymers. The applied PUR composition was methylene diphenyl 2, 4'-diisocyanate (MDI), methylene diphenyl 4, 4'diisocyanate butanediol, polytetrahydrofuran. ${ }^{15}$ It is a non-biodegradable polymer, $\mathrm{Tg}=40^{\circ} \mathrm{C}$.

We applied PURAC PURASORB PDLG 5010 DL-lactic acid / glycolic acid 50:50 copolymer (PDLG). It is a biocompatible and biodegradable polymer, $\varrho=1.24 \mathrm{~kg} / \mathrm{L}$ density, $\mathrm{IV}=1.04$ $\mathrm{dL} / \mathrm{g}$ inherent viscosity, $\mathrm{MW}=104 \mathrm{kDa}$ molecular weight, $\mathrm{Tg}=42{ }^{\circ} \mathrm{C}$.

\subsection{Creating the coating}

1,2 , and $3 \mathrm{wt} \%$ concentration solutions were made from the polymers. PDLG was dissolved in acetone, and PUR was dissolved in tetrahydrofuran. Stainless steel sheets were put into the solutions for 3 seconds then they were removed from the solutions at a speed of $5 \mathrm{~mm}$ per 
second. We created one-layer coatings at room temperature.

\subsection{Adhesion test}

Each freshly coated sample was stacked to overlap part of another same-size steel sheet. Pairs of parallel sheets in flat-face contact were left to dry for one day in a constant air steam. Stucktogether samples were then pulled in opposite directions within the carrier-sheet plane (Figure 1).

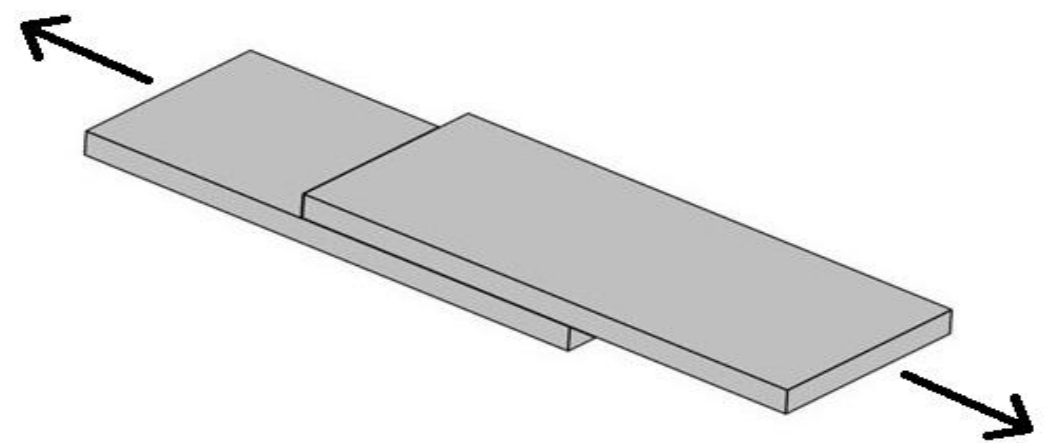

Fiure. 1. Schematic figure of each two-sheet sample as left to dry. Same-size surface-treated steel sheets were flat-face stacked like this after coating. In later tests we pulled the sheets in the two directions shown here by arrows

We varied the contact area from $10 \mathrm{~mm} \times 10 \mathrm{~mm}$ to $10 \mathrm{~mm} \times 20 \mathrm{~mm}$ with the narrower sheets, and from $20 \mathrm{~mm} \times 10 \mathrm{~mm}$ to $20 \mathrm{~mm} \times 20 \mathrm{~mm}$ with the broader sheets (Figure 2).
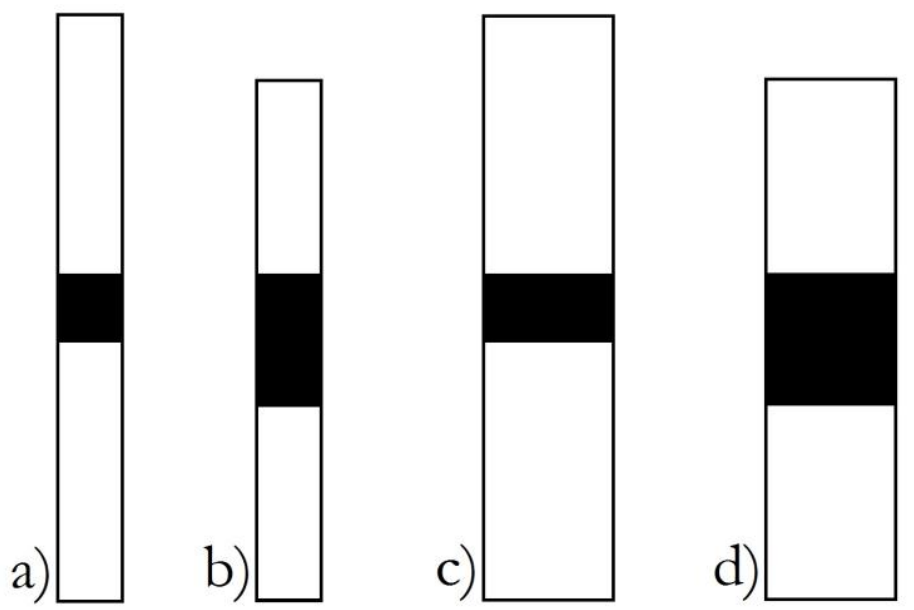

Figure 2. Schematic figure of each overlap area between pairs of adhering sheets a) $10 \mathrm{~mm} \times 10 \mathrm{~mm}$ narrower b) $10 \mathrm{~mm} \times 20 \mathrm{~mm}$ narrower c) $20 \mathrm{~mm} \times 10 \mathrm{~mm}$ broader d) $20 \mathrm{~mm} \times 20 \mathrm{~mm}$ broader.

During the separation by sliding, force $(\mathrm{N})$ was measured as a function of displacement $(\mathrm{mm})$. Motion was set at $4 \mathrm{~mm}$ per minute in every case. From the maximum values we got from experiments we deduced the relationship between the coating and the stainless steel sheet carrier. An Instron type 5965 tensile machine was used. 


\section{Results}

We measured the surface roughness of the carriers, and the adhesion of polymer coatings from different solutions on various surface-treated and size carriers.

\subsection{Surface roughness}

Sheet surface texture was compared to electropolishing time. No other parameters varied. Average surface roughness $\left(\mathrm{R}_{\mathrm{a}}\right)$ fell with increased electropolishing time. Higher roughness peaks are broken down by this surface treatment. Rough surfaces can adhere better. Figure 3 shows the test results and Table 1 average surface roughness $\left(\mathrm{R}_{2}\right)$.

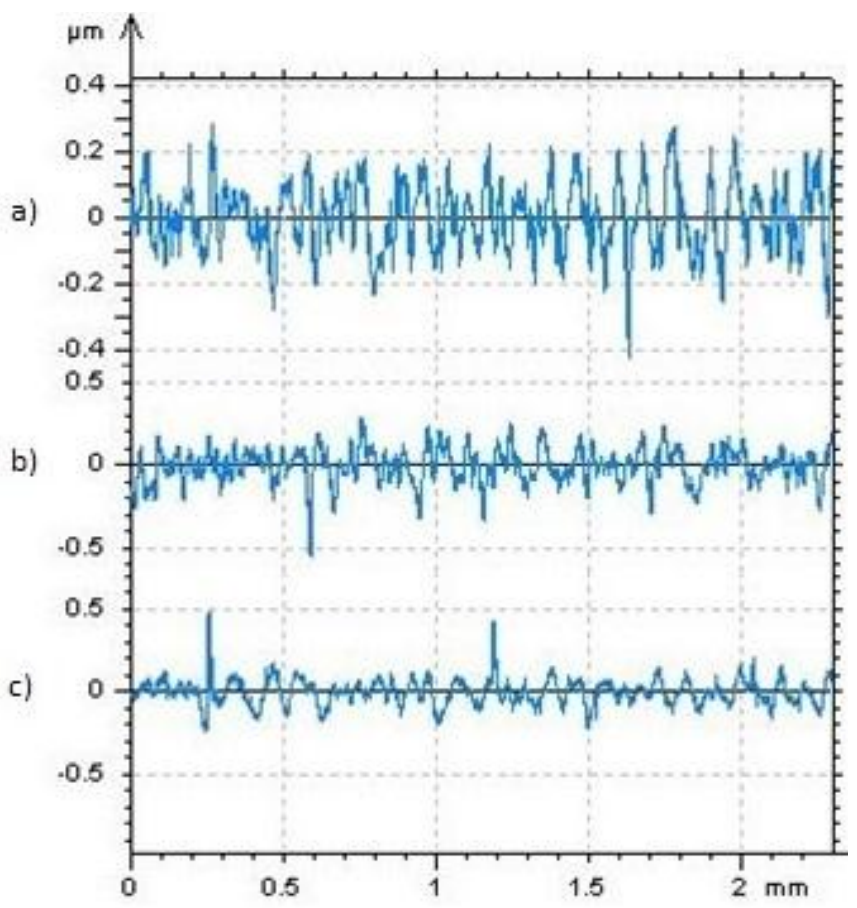

Figure 3. Electropolished stainless steel sheet surface roughness tests at a) $t=180 \mathrm{sec}, \mathrm{b}) \mathrm{t}=210 \mathrm{sec}, \mathrm{c}) \mathrm{t}$ $=240 \mathrm{sec}$

\begin{tabular}{|l|l|l|l|}
\hline Electropolishing time $(\mathrm{s})$ & 180 & 210 & 240 \\
\hline $\mathrm{R}_{\mathrm{a}}(\mu \mathrm{m})$ & $0.1063 \pm 0.0332$ & $0.0913 \pm 0.0078$ & $0.0899 \pm 0,0312$ \\
\hline
\end{tabular}

Table 1. Treated stainless steel sheets' surface roughness. More time spent electropolishing gave a smoother surface

\subsection{Adhesion of coating}

All the coating types were tested three times with this method. Figure 4 shows a typical tensile diagram similar to that for other samples. From these kinds of diagrams we took the maximums. 
Averages of each three measurement were counted. Averages were devided the appropriate contacted areas. Adhesion was characterized with a unified comparable unit $\left(\mathrm{N} / \mathrm{mm}^{2}\right)$.

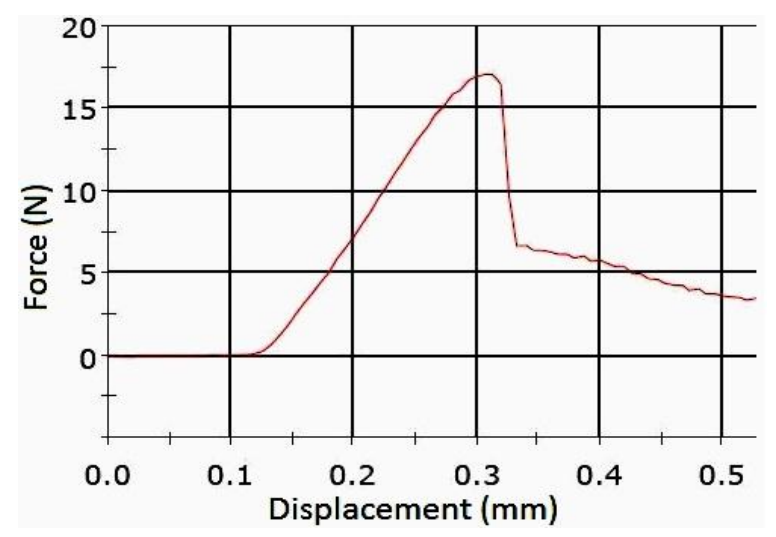

Figure 4. One sample's adhesion test

During our experiments it was found that measurements with broader samples were less accurate (Figure 5). If a sheet's surface is not completely flat, the surfaces are not in close contact. The uneven roughness of the sample may have occurred during sample preparation. This phenomenon creates inaccuracies in the measurements. The narrower ones caused no measuring problems. This can be observed on the narrower $200 \mathrm{~mm}^{2}$ samples.

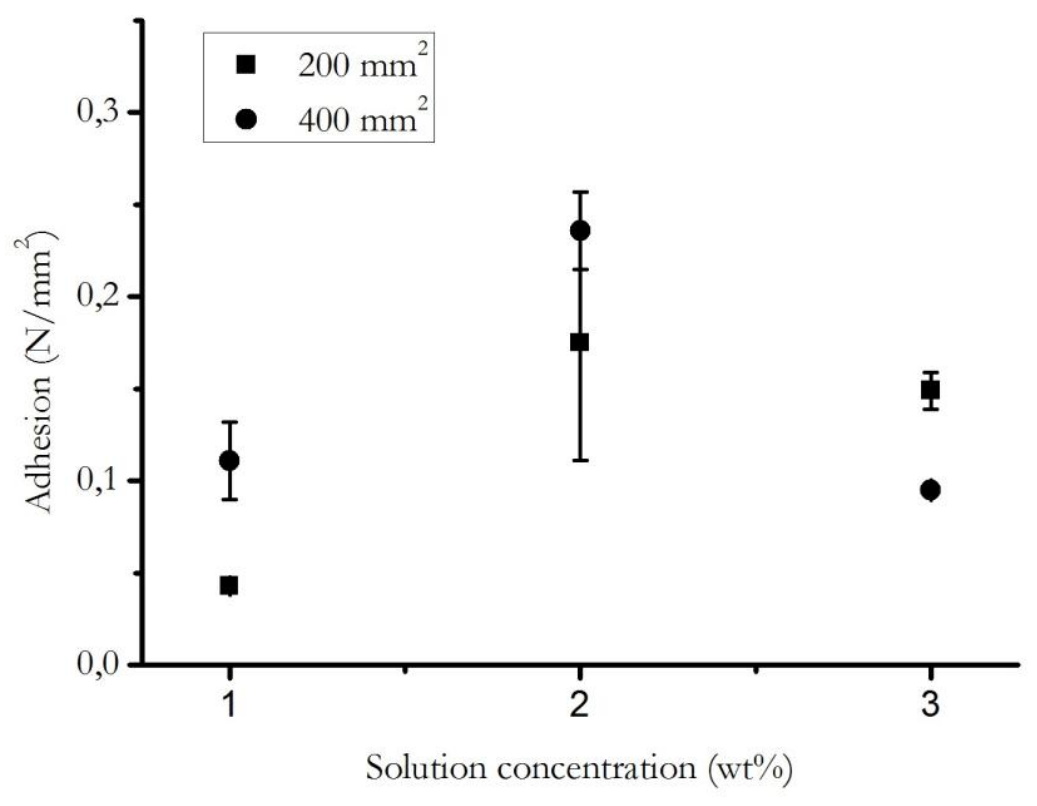

Fig. 5. Adhesion test results of the PUR coating on broader sheets. Imperfectly flat surfaces led to inaccuracies

Based on our previous experiments, we expected adhesion to worsen with increased electropolishing time. This statement was true in one case, the $1 \mathrm{wt} \%$ PDLG solution coatings (Figure 6). So in coatings made from less polymer the determining factor is steel-sheet surface roughness after electropolishing and before polymer coating. Higher average roughness provides better adhesion. 


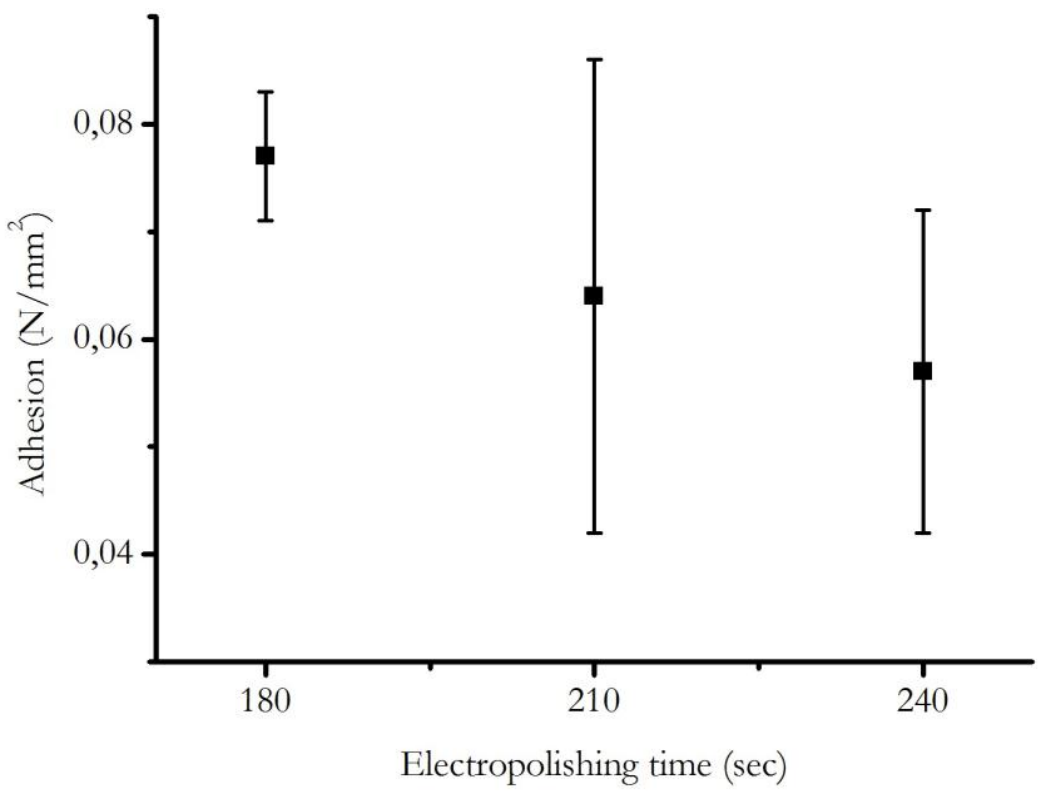

Fig. 6. Adhesion test results for the coating made from $1 \mathrm{wt}^{0} \%$ PDLG, area in contact $100 \mathrm{~mm}^{2}$. The smoother surface created by electropolishing caused weaker adhesion

Increasing polymer solution concentrations increased adhesion. With more continuous coating polymer-metal interaction become stronger. It can be observed in both polymers, PDLG and PUR. Figure 7 shows that under the same conditions, PUR has better adhesion than PDLG.

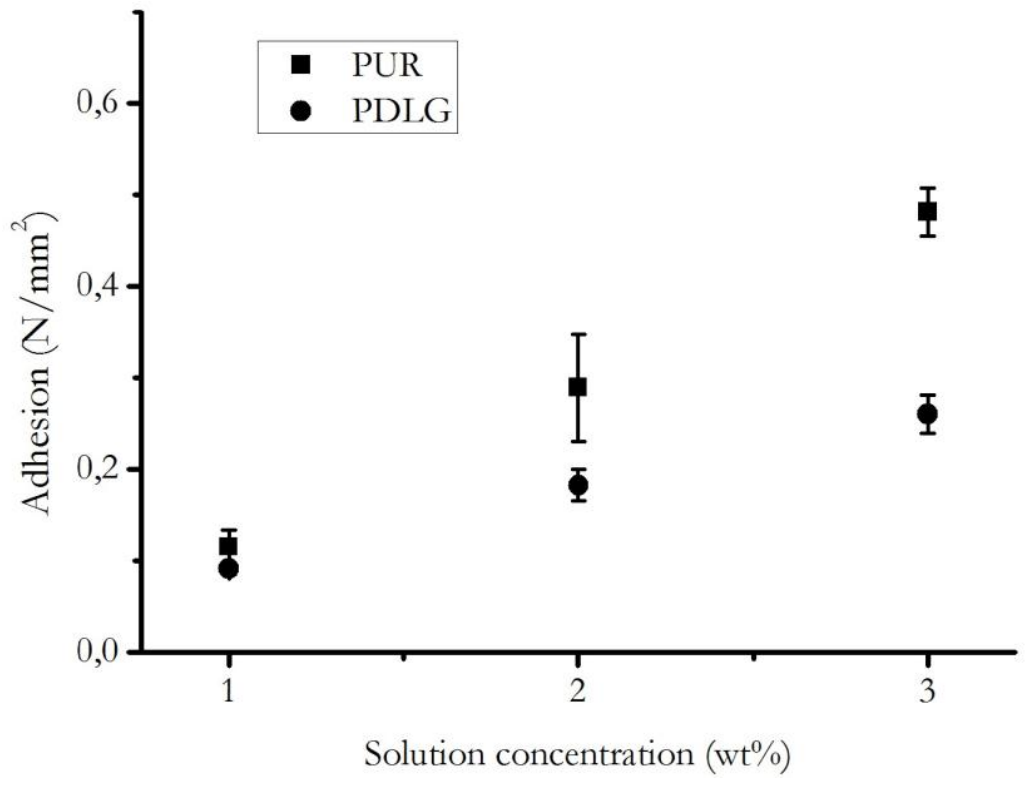

Figure 7. Comparing PUR and PDLG coating adhesion to solution concentration. Contact area was 100 $\mathrm{mm}^{2}$, sheets were electropolished for $180 \mathrm{sec}$. PUR had better adhesion than PDLG

\section{Conclusion}

We developed a systematic method to examine coating layers' strength of adhesion. We anticipate using it to classify and compare future coatings. 
During our experiments we laid down biocompatible coatings onto stainless steel carrier sheets. We found that the technique we developed is appropriate if the area in contact is at least 100 $\mathrm{mm} 2$ and the carrier surface is as plain as possible.

Furthermore we conclude that from the two studied polymers, the PUR has better adhesion on surface-treated stainless steel 304 type carrier.

\section{REFERENCES}

1. Hildebrand HF, Blanchemain N, Mayer G, Chai F, Lefebvre M, Boschin F. Surface coatings for biological activation and functionalization of medical devices. In: Surface and Coatings Technology. EMRS 2005 Symposium K - Protective Coatings and Thin Films: 2005 May 31 - June 3: Strasbourg(FR) 2006;200(22-23):6318-24.

2. Mani G, Feldman MD, Patel D, Agrawal CM. Coronary stents: A materials perspective. Biomaterials 28 2007. p. 1689-1710.

3. Fang HW, Li KY, Su TL, Yang TCK, Chang JS, Lin PL, Chang WC. Dip coating assisted polylactic acid deposition on steel surface: Film thickness affected by drag force and gravity. Material Letters 2008;62(21-22):3739-41.

4. Ollendorf H, Schneider D. A comparative study of adhesion test methods for hard coatings. Surface and Coatings Technology 1999:113(1-2):86-102.

5. Cortés EV, Lorenzo MA, Jirsa JO, Wheat HG, Carrasquillo RL. Adhesion Testing of Epoxy Coating. Texas Department of Transportation: 1998 Sept.

6. Ozsváth P, Bognár E. Sztentbevonatok tapadásának vizsgálata és fejlesztése. (Examination and investigation of stent coating's adhesion). Anyagok világa 2010. p. 1.

7. Litteken CS, Dauskardt RH. Adhesion of polymer thin-films and patterned lines. International Journal of Fracture 2003;119/120:475-85.

8. Sélley TL, Terdik A, Bognár E. Biológiailag lebomló polimerbevonatok tapadásának vizsgálata (Investigation of biodegradable polymer coatings' adhesion test). Fiatal Múszakiak Tudományos Ülésszaka XVIII: 2013 March 21-22: Kolozsvár (RO)

9. Sélley TL, Szilágyi A, Bognár E. Biodegradable Ploymer coatings for stents. 29th Danubia - Adria Symposium on Advances in Experimental Mechanics: 2012 Sept 26 - 29: Belgrade (SRB)

10. Newson T. Stainless Steel - A Family of Medical Device Materials. This article first appeared in Business Briefing: Medical Device Manufacturing \& Technology 2002: London (UK).

11. Smith RW: New Developments and Trends in Medical-grade Adhesives. Medical Device Manufacturing \& Technology 2004: London (UK)

12. Onuki Y, Bhardwaj U, Papadimitrakopoulos MPF, Burgess DJ. A Review of the Biocompatibility of Implantable Devices: Current Challenges to Overcome Foreign Body Response. J Diabetes Sci Technol. 2008 November;2(6):1003-15.

13. Anderson JM, Shive MS. Biodegradation and biocompatibility of PLA and PLGA microspheres. Advanced Drug Delivery Reviews 1997;28:5-24.

14. Raval A, Choubey A, Kotadia H, et al. Novel Biodegradable Polymeric Matrix Coated Cardiovascular Stent For Controlled Drug Delivery. Trends Biomater. Artif. Organs 2007;2:101-10.

15. Fejős D, Sütő P, Molnár K, Pukánszky B. PU/PBT keverékek vizsgálata esetleges orvosi alkalmazásra. (Examination of PU / PBT blends for possible medical applications). Múanyag és Gumi 2011;48(12): 446-9. 
This work is connected to the scientific programme of the "Development of qualityoriented and harmonized $R+D+I$ strategy and functional model at BME" project. This project is supported by the New Hungary Development Plan (Project ID: TÁMOP4.2.1/B-09/1/KMR-2010-0002).

The work reported in the paper has been developed in the framework of the project "Talent care and cultivation in the scientific workshops of BME" project. This project is supported by the grant TÁMOP-4.2.2.B-10/1--2010-0009.

Many thanks go to Esther Kooijman at PURAC, who provided the PDLG and Kinga Molnár, who provided the PUR we used. 